\title{
Effect of Dementia Training on Knowledge and Attitude Among Long-Term Care Staff in Yogyakarta, Indonesia
}

\author{
Sri Mulyani*(D), Azam David Saifullah (D) \\ Department of Mental Health and Community Nursing, Faculty of Medicine, Public Health and Nursing, Universitas Gadjah \\ Mada, Yogyakarta, Indonesia
}

Edited by: Sasho Stoleski Citation: Mulyani S, Saifullah AD. Effect of Dementia Training on Knowledge and Attitude Among Long-Term Care Staff in Yogyakarta, Indonesia. Open Access Maced J Med Sci. 2021 Aug 08; 9(E):592-597. https://doi.org/10.3889/oamjms.2021.6392 Keywords: Alzheimer's disease; Attitude; Dementia; Long-term care staff; Knowledge; Training Correspondence: Sri Mulyani, Department of Menta Health and Community Nursing, Faculty of Medicin Indonesia. E-mail: srimulyani@uh Mada Received: 03-May-202 Revised: 19-May-202 Accepted: 29-Jul-202 Copyright: $\odot 2021$ Sri Mulyani, Azam David Saifullah Funding: This study was supported by the School of Nursing, Faculty of Medicine, Public Health and Nursing, Universitas Gadjah Mada under the 2019 community service grant program Competing Interest: The authors have declared that $\mathrm{n}$ competing interest exists
Open Access: This is an open-access article distributed onCommercial 4.0 International License (CC BY-NC 4.0)

\section{Background}

The Global Burden of Disease in 2016 stated that there were 43.8 million people with dementia worldwide (equivalent to $0.59 \%$ of the world population) [1]. It is estimated that the number of people living with dementia in the world will reach 75 million by the year 2030. In addition, the number will continue to grow to 132 million by 2050 [2]. In the past 50 years (19712018), the percentage of elderly people in Indonesia approximately doubled. In 2019 , the aging population in Indonesia was estimated to increase to 27.5 million or $10.3 \%$ [3]. Furthermore, according to census data in 2015 , the Special Region of Yogyakarta has the highest percentage of elderly people (13.6\%) [4].

As the number of the elderly population raises, age-related diseases such as dementia are also increasing [5]. Dementia is classified as a disease that causes a decline in mental function and overall memory loss [6]. In addition to decreased cognitive function, people with dementia are also at risk of developing other comorbidities. It can make them at higher chance of being treated in an acute condition in a hospital [7]. Persons with dementia often lose their ability to manage themselves and carry out their responsibilities [8], while they have complex needs and are unable to express their needs precisely [9]. Therefore, they need more assistance to fulfill their needs, including from the longterm care staff who can help with these responsibilities when family members cannot [8].

Long-term care staffs have challenges to improve their knowledge and competence to provide quality skilled services to meet patient needs, and the number of trained staff is smaller compared to the number of elderly who rely on their services [10]. Various studies found that there is rarely an appropriate treatment for dementia because of the underdeveloped care in developing countries [11], [12].

Effective dementia care education programs should be targeted to meet the learning objectives of health professionals [13]. Training and education are important and essential for nurses to be more proactive in early detection of dementia, considering the high incidence of undiagnosed dementia [7].

There is no particular care for the elderly with dementia in Indonesia. However, there are places that provide care for the elderly where many patients are suffering from dementia, and one of them is called Balai 
Pelayanan Social Tresna Werdha Abiyoso (BPSTW). It is a long-term care center for the elderly with social and economic problems under the social authorities of the Special Region of Yogyakarta. The nurses, informal caregivers, and social workers in BPSTW have mostly never received training related to dementia, although there are many elderly suffering from dementia in this place.

Health worker training has its own challenges, such as improving the knowledge and skills with objectives of becoming skilled professionals to provide the patients' optimal care [5]. However, there is limited research related to training for staff who works to provide care for people with dementia so far. This research aimed to determine the knowledge and behavior of the BPSTW Abiyoso staff and the effect of dementia training there.

\section{Instruments and Methods}

This research was a pre-experimental study using one-group pre-test and post-test study method. The research participants were 30 staffs recruited by the convenience sampling method consisting of nurses, social workers, servants, helpers, and securities with various educational levels at BPSTW Abiyoso. The staffs who participated in the training have direct contact with the elderly at BPSTW Abiyoso on a daily basis.

The instruments in this research consisted of Dementia Knowledge Assessment Scale (DKAS) and Dementia Attitudes Scale (DAS). The DKAS was employed to measure staff's knowledge about dementia. The DKAS was developed by Annear et al. in 2015. The DKAS has 25 statements involving the following topics: (1) Causal and characteristics, (2) communication and ODD behavior, (3) care considerations, and (4) "Risks and Health Promotion." DKAS score ranging from 0 to 50. The Indonesian version of DKAS was developed using the Brislin model for instrument translation, resulting as a valid questionnaire with the S-CVI of the Indonesian version of DKAS of 1.00 [14]. The DKAS has an acceptable reliability with Cronbach's alpha of 0.674 [15]. Meanwhile, the DAS was used to measure attitudes toward person with dementia (PWD). The DAS was developed by Melissa L. O'Connor and Susan [16]. The DAS has 20 items with Likert scale which ranged from "strongly agree" to "strongly disagree" and has two factors labeled with "dementia knowledge" and "social comfort" [16]. The Indonesian version of the DAS was also developed using the Brislin model for instrument translation, resulting as a valid questionnaire with the S-CVI of the Indonesian version of DKAS of 0.99. The DAS has an acceptable reliability with Cronbach's alpha of 0.754 [14].
The research procedure was approved by the related authorities. The research was conducted with permission from the head of BPSTW Abiyoso. The head of BPSTW Abiyoso determined the staff who participated in the training with the following inclusion criteria: the staffs who are interacting directly with the elderly, willing to take part in the training for 2 consecutive days in July 24-25, 2019 , and willing to participate in the research by completing the informed consent form. A pre-test was conducted for all of the participants before the training started. Then, it was followed by training for 2 days and a post-test. Dementia Care Skills (DCSs) for care workers were used as the training material which was given for $18 \mathrm{~h}$ by two certified trainers from Alzheimer's Disease International (ADI) as well as Alzheimer Indonesia. It consists of four modules including understanding dementia, person-centered care and communication in dementia, behavioral and psychological symptoms of dementia (BPSD), and meaningful engagement with PWDs. The method to deliver this training was a combination of lectures, discussion, role-play, and experiential learning as a standard educational approach for DCS from ADI and Alzheimer Indonesia.

\section{Data analysis}

SPSS version 26 was used to manage and analyze the data. Normality test was performed to identify the distribution of total scores in the DKAS and DAS. Both DKAS and DAS scores were normally distributed. The central tendency of the data was presented using mean and standard deviation (SD) for continuous data, while frequency and percentage were used to present the categorical data. Paired t-tests were utilized to identify the correlation of pre and post measurement of knowledge (DKAS) and attitude (DAS).

\section{Results}

Thirty staffs participated in the training, but only 28 data were analyzed because two staffs did not complete the questionnaire. The staffs are mostly female, had finished compulsory education, namely, high school degree, and did not have any previous training in dementia (Table 1).

The pre-test results on DKAS showed a mean value of $19.89 \pm 7.80$ (out of a maximum score of 50 , Table 2). The value increased by 8.96 points in the posttest (28.86; SD 8.73). The gain in the total DKAS score was statistically significant with a value of $t=4.78$ $(p=0.00)$. The highest gain of DKAS score occurred in the care consideration domain for about 3.5 points $(t=$ 
Table 1: Characteristics of research respondents $(\mathrm{N}=28)$

\begin{tabular}{|c|c|c|c|}
\hline Variable & Mean \pm SD & $f$ & $\%$ \\
\hline Age & $39.36 \pm 8.89$ & & \\
\hline \multicolumn{4}{|l|}{ Sex } \\
\hline Male & & 12 & 42.9 \\
\hline Female & & 16 & 57.1 \\
\hline \multicolumn{4}{|l|}{ Education background } \\
\hline Compulsory education & & 18 & 64.3 \\
\hline Higher education & & 10 & 35.7 \\
\hline \multicolumn{4}{|l|}{ Previous dementia training } \\
\hline Yes & & 4 & 14.3 \\
\hline No & & 24 & 85.7 \\
\hline \multicolumn{4}{|l|}{ Occupation in BPSTW } \\
\hline Nurse & & 6 & 21.4 \\
\hline Staff & & 22 & 78.6 \\
\hline
\end{tabular}

$5.04, p=0.00)$. Then, the next high gain occurred in the causal and characteristic domain for about 2.89 points $(t=4.54, p=0.00)$, and difference in the communication and ODD behavior domain was 1.5 points $(t=2.6, p=$ 0.015). Meanwhile, the improvement in the risk factors and health promotion domain for about 1.07 was not statistically significant $(t=1.76, p=0.09)$.

Table 2: Distribution of staff knowledge about people with dementia $(\mathbf{N}=\mathbf{2 8})$

\begin{tabular}{|c|c|c|c|c|c|c|c|c|}
\hline $\begin{array}{l}\text { Variable } \\
\end{array}$ & $\begin{array}{l}\text { Mean } \pm \\
\text { SD } \\
\text { pre-test }\end{array}$ & $\begin{array}{l}\text { Mean } \pm \\
\text { SD } \\
\text { post-test }\end{array}$ & $\begin{array}{l}\text { Mean } \\
\text { difference }\end{array}$ & Correlation & $p$ & $\begin{array}{l}\text { paired } \\
\text { t-test }\end{array}$ & df & $\mathrm{p}$ \\
\hline \multicolumn{9}{|l|}{$\begin{array}{l}\text { Knowledge of } \\
\text { dementia }\end{array}$} \\
\hline $\begin{array}{l}\text { Total score of } \\
\text { DKAS }\end{array}$ & $\begin{array}{l}19.89 \pm \\
7.80\end{array}$ & $\begin{array}{l}28.86 \pm \\
8.73\end{array}$ & -8.96 & 0.282 & 0.146 & -4.776 & 27 & 0.000 \\
\hline $\begin{array}{l}\text { Domain } 1 \\
\text { causal and } \\
\text { characteristics }\end{array}$ & $\begin{array}{l}3.50 \pm \\
2.03\end{array}$ & $\begin{array}{l}6.39 \pm \\
3.61\end{array}$ & -2.89 & 0.397 & 0.037 & -4.542 & 27 & 0.000 \\
\hline $\begin{array}{l}\text { Domain } 2 \\
\text { risk factors } \\
\text { and health } \\
\text { promotion }\end{array}$ & $\begin{array}{l}5.14 \pm \\
2.66\end{array}$ & $\begin{array}{l}6.21 \pm \\
2.49\end{array}$ & -1.07 & 0.219 & 0.263 & -1.761 & 27 & 0.090 \\
\hline $\begin{array}{l}\text { Domain } 3 \\
\text { communication } \\
\text { and ODD } \\
\text { behavior }\end{array}$ & $\begin{array}{l}4.50 \pm \\
2.60\end{array}$ & $\begin{array}{l}6.00 \pm \\
1.94\end{array}$ & -1.50 & 0.124 & 0.528 & -2.603 & 27 & 0.015 \\
\hline $\begin{array}{l}\text { Domain } 4 \text { care } \\
\text { consideration } \\
\text { Attitudes toward } \\
\text { dementia }\end{array}$ & $\begin{array}{l}6.75 \pm \\
2.93\end{array}$ & $\begin{array}{l}10.25 \pm \\
2.78\end{array}$ & -3.50 & 0.172 & 0.383 & -5.037 & 27 & 0.000 \\
\hline $\begin{array}{l}\text { Total score of } \\
\text { DAS }\end{array}$ & $\begin{array}{l}95.75 \pm \\
11.60\end{array}$ & $\begin{array}{l}102.18 \\
\pm 13.14\end{array}$ & -6.43 & 0.653 & 0.000 & -3.269 & 27 & 0.003 \\
\hline Social comfort & $\begin{array}{l}46.07 \pm \\
6.77\end{array}$ & $\begin{array}{l}49.25 \pm \\
8.61\end{array}$ & -2.89 & 0.665 & 0.000 & -2.584 & 27 & 0.016 \\
\hline $\begin{array}{l}\text { Dementia } \\
\text { knowledge }\end{array}$ & $\begin{array}{l}49.68 \pm \\
6.95\end{array}$ & $\begin{array}{l}52.93 \pm \\
7.55\end{array}$ & -1.07 & 0.538 & 0.003 & -2.460 & 27 & 0.021 \\
\hline
\end{tabular}

The total DAS score result showed a mean value of 95.75 ; SD 11.60. The score increased to 102.18 ; SD 13.14 , a gain of 6.43 points was statistically significant $(t=3.27, p=0.003)$. The statistically significant improvement also occurred in each DAS area including the social comfort domain (mean difference $=2.89, \mathrm{t}=2.59, \mathrm{p}=0.016)$ and dementia knowledge (mean difference $=1.07, \mathrm{t}=2.46$, $\mathrm{p}=0.021$ ).

Overall, based on the training results in Table 2, there was a significant score improvement $(p<0.05)$ between the knowledge variable before and after training, and between the attitudes variable before and after training.

Based on age and gender of the participants, there was no significant difference in their knowledge and attitude of dementia between pre-test and post-test (Table 3 ). The baseline measurement of
Table 3: Knowledge and attitude toward PWD based on participant's characteristics $(\mathrm{N}=\mathbf{2 8})$

\begin{tabular}{|c|c|c|c|c|c|c|c|c|}
\hline \multirow{3}{*}{ Variable } & \multicolumn{4}{|c|}{ Knowledge } & \multicolumn{4}{|l|}{ Attitude } \\
\hline & \multicolumn{2}{|l|}{ Pre-test } & \multicolumn{2}{|c|}{ Post-test } & \multicolumn{2}{|c|}{ Pre-test } & \multicolumn{2}{|c|}{ Post-test } \\
\hline & $\mathrm{r} / \mathrm{t}$ & $p$ value & $\mathrm{r} / \mathrm{t}$ & $p$ value & $\mathrm{r} / \mathrm{t}$ & $p$ value & $\mathrm{r} / \mathrm{t}$ & $p$ value \\
\hline Age & 0.087 & 0.659 & -0.194 & 0.322 & 0.133 & 0.499 & -0.159 & 0.418 \\
\hline Gender & 0.303 & 0.765 & -.972 & 0.343 & -1.759 & 0.092 & -0.954 & 0.350 \\
\hline $\begin{array}{l}\text { Education } \\
\text { background }\end{array}$ & -1.114 & 0.286 & -4.415 & 0.000 & -2.350 & 0.027 & -2.260 & 0.037 \\
\hline Previous training & -.576 & 0.601 & 0.767 & 0.483 & 0.441 & 0.686 & 2.395 & 0.083 \\
\hline Occupation & 0.137 & 0.895 & 4.575 & 0.000 & 1.908 & 0.090 & 1.999 & 0.090 \\
\hline
\end{tabular}

knowledge showed that there was no significant difference between compulsory or higher education group. However, there was a statistically significant difference in knowledge at the post-intervention based on education background $(p=0.000)$. Meanwhile, there was already a statistical significance difference on the attitude in education background in the pre-test $(p=0.027)$, in which the higher education group scored higher DAS compared to the compulsory education background group. These results were similar in the post-test $(p=0.037)$. Findings also showed that attitude toward dementia was not statistically different after training based on their previous dementia training. Furthermore, while there was a statistically significant improvement of knowledge of dementia between nurses and staff (occupation based), there was no statistically significant difference in their attitudes toward PWD based on their occupation (Table 3).

\section{Discussion}

\section{Knowledge of dementia}

The research aimed to identify the effect of dementia training on the knowledge and attitudes of nursing home staff in providing services to the elderly with dementia. Knowledge of dementia is extremely essential in PWD services. One major reason for poor outcome of dementia services in hospitals is inadequate knowledge and skills of the staff [17]. Based on the pre-test result of this study (Table 2), knowledge of the staff is inadequate, especially on the causal and characteristics of dementia domain. These results are in line with a study conducted by Scerri and Scerri in 2013 that showed the research respondents knowledge scores were low on aspects related to knowledge of dementia in general (such as the most common form of dementia), the consequences of dementia, and appropriate treatment for PWD [18].

After the training, there was a significant gain in scores on the knowledge variable in all domains $(p=0.000)$ (Table 2). Change in the care consideration domain was statistically significant and had the highest improvement $(p=0.000)$. The gain in knowledge scores 
in these domains is in line with the study results of Scerri and Scerri in 2013 which indicated that the training is able to significantly increase staff knowledge. Therefore, the staffs are more sensitive to the patients' behavior [18].

All domains had significantly increased scores, but the improvement of risk factors and health promotion domain was not statistically significant $(p=0.09)$. The majority of the scores were significantly increased, indicating that staff knowledge was more adequate than before the training. The adequate knowledge will effect critical thinking in service delivery and improve client outcomes [12], [19].

Comprehensive knowledge influences the way health workers express their emotions and feelings in providing empathy and care when assisting dementia patients [20]. The exploratory result found that nurses and other health professionals who have positive attitudes scored remarkably high in the dementia knowledge domain [5]. In a similar study, it showed that staffs who have positive attitudes toward PWD and their families had significantly higher mean scores on the knowledge aspect [18].

\section{Attitude toward dementia}

The attitude toward PWD is one of the determining factors for quality services toward PWD. Beside the poor staff knowledge and skills, other reasons that affect the poor outcome of dementia services are stigma and negative behavior from staff toward PWD [17]. In the staff attitude assessment, the higher score achieved indicated the more positive attitudes toward PWD [21]

After the training, there was a significant improvement in the overall attitudes score $(p=0.003)$. It indicated that all the staffs experienced an improvement in positive attitudes in dealing with PWD. Significant changes in attitudes were in the social comfort domain $(p=0.016)$ and dementia knowledge domain $(p=0.021)$. Positive attitude improvements are related to social comfort domain including the staff feeling more familiar with dementia and the satisfaction in providing care to the PWD. These results are consistent with the previous studies which stated that training programs are able to improve nurses' positive attitudes. Furthermore, it can increase nurse satisfaction and confidence in providing services to PWD. Nurses' positive attitudes in the care delivery are able to improve the well-being of PWD [19], [22].

\section{Knowledge and attitude toward PWD based on participant's characteristics}

In this study, as shown in the correlation test (Table 3), there was no association between age toward knowledge and attitudes of the staff about PWD. These results are in line with a study conducted by Åström et al. in 1991 which did not reveal any differences in attitudes toward PWD related to the staff age [21]. However, other studies mentioned that education, age, communication skill level, ethical dilemma, and psychological factors in care delivery potentially affect nurses' attitudes toward PWD [19].

In the education level correlation test, there was a significant association between educational level toward knowledge after training $(p=0.000)$ and attitudes after training $(p=0.037)$. These results are in line with research conducted by Martin et al. in 2016 which mentioned that education for health-care providers significantly affects their opinion, confidence, knowledge, and attitudes in engaging with dementia patients [23]. Staff education and training are some of the major points in the measurements to improve the quality of care and the expected outcomes of PWD in the hospital [24].

Previous dementia training attended by several staff showed no significant association to the knowledge and attitudes of the staff both before and after training. These results are dissimilar to the results from research conducted by Elvish et al. 2014 which stated that the quality of hospital service improvement is affected by the staff knowledge and skills in working with dementia related to their training experience [25]. Kuske et al. in 2009 also found a different result. They mentioned that training experience in dementia patient services has an essential role in determining the quality of sustainable care [26]. However, there were no further data in this research regarding when the training was conducted and the content of the training.

\section{Conclusions}

After the training, participants' knowledge increased significantly in all domains. However, the improvement in risk factors and health promotion domain was not statistically significant. Participants' attitudes toward PWD improved significantly after the training. The significant gain occurred in all domains (social comfort and dementia knowledge). It can be concluded that the training is able to increase the staff knowledge and attitudes toward people with dementia. It is recommended to provide DCS training for staff and health workers in nursing homes.

\section{Acknowledgment}

We would like to express our thanks to Dementia Australia for developing the training, Alzheimer's Disease Association, Singapore, and Asia Pacific region of Alzheimer's Disease International 
for making the training available in South East Asian culture, and Alzheimer's Indonesia regarding to the support in using of the training in this study. The funding of this project was supported by the School of Nursing, Faculty of Medicine, Public Health, and Nursing, Universitas Gadjah Mada under the 2019 community service grant program.

\section{References}

1. GBD 2016 Dementia Collaborators. Global, regional, and national burden of Alzheimer's disease and other dementias, 1990-2016: A systematic analysis for the Global Burden of Disease Study 2016. Lancet Neurol. 2019;18(1):88-106. https:// doi.org/10.1136/bmj.194

PMid:30497964

2. Vissenberg R, Uysal $O$, Goudsmit $M$. Barriers in providing primary care for immigrant patients with dementia: GPs' perspectives. BJGP Open. 2018;2(4):101610. https://doi. org/10.3399/bjgpopen18x101610

PMid:30723796

3. Badan Pusat Statistik. Statistik Penduduk Lanjut Usia 2017. Jakarta: Badan Pusat Statistik; 2018. https://doi.org/10.31002/ rep.v5i2.3431

4. Bappenas, BPS-Statistics Indonesia, UNFPA. Proyeks Penduduk Indonesia 2015-2045, Hasil SUPAS 2015. Jakarta: BPS-Statistics Indonesia; 2018.

5. Adler G, Lawrence BM, Ounpraseuth ST, Asghar-Ali AA. A survey on dementia training needs among staff at communitybased outpatient clinics. Educ Gerontol. 2015;41(12):903-15. https://doi.org/10.1080/03601277.2015.1071549

6. Scerri A, Innes A, Scerri C. Person-centered dementia care in acute hospital wards The influence of staff knowledge and attitudes. Geriatr Nurs (Minneap). 2019;41(3):215-27. https:// doi.org/10.1016/j.gerinurse.2019.09.001

7. Alzheimer's Association. 2018 Alzheimer's disease facts and figures. Alzheimers Dement. 2018;14(3):367-429. https://doi. org/10.1016/j.jalz.2018.02.001

PMid:32157811

8. Pohontsch NJ, Scherer M, Eisele M. (In-) formal caregivers and general practitioners' views on hospitalizations of people with dementia: An exploratory qualitative interview study. BMC Health Serv Res. 2017;17:530. https://doi.org/10.1186/ s12913-017-2484-9

PMid:28778160

9. Pinkert C, Faul E, Saxer S, Burgstaller M, Kamleitner D, Mayer $\mathrm{H}$. Experiences of nurses with the care of patients with dementia in acute hospitals: A secondary analysis. J Clin Nurs. 2017;27(1-2):162-72. https://doi.org/10.1111/jocn.13864 PMid:28426891

10. Dreier A, René J, Eichler T, Hoffmann W. Qualifications for nurses for the care of patients with dementia and support to their caregivers: A pilot evaluation of the dementia care management curriculum. Nurse Educ Today. 2016;36:310-7. https://doi. org/10.1016/j.nedt.2015.07.024 PMid:26277428

11. Wang $Y$, Dongxia L, Ullah S, He G, De Bellis A. Evaluation of a nurse-led dementia education and knowledge translation programme in primary care: A cluster randomized controlled trial. Nurse Educ Today. 2017;49:1-7. https://doi.org/10.1016/j. nedt.2016.10.016

\section{PMid:27855297}

12. Poreddi V, Carpenter BD, Gandhi S, Chandra R, BadaMath S Knowledge and attitudes of undergraduate nursing students toward dementia: An Indian perspective. Invest Educ Enferm. 2015;33(3):519-28. v33n3a16

\section{PMid:28569960}

13. Kimzey M, Clinical A, Mastel-smith B, Alfred D. The impact of educational experiences on nursing students' knowledge and attitudes toward people with Alzheimer's disease: A mixed method study. Nurse Educ Today. 2016;46:57-63. https://doi. org/10.1016/j.nedt.2016.08.031 PMid:27598794

14. Sunaryo SR, Saifullah AD, Mulyani S. Knowledge and attitudes toward people with dementia among nursing students in Yogyakarta, Indonesia. Belitung Nurs J. 2020;6(6):196-202. https://doi.org/10.33546/bnj.1178

15. Ursachi G, Horodnic IA, Zait A. How reliable are measurement scales? External factors with indirect influence on reliability estimators. Proc Econ Finance. 2015;20(15):679-86. https://doi. org/10.1016/s2212-5671(15)00123-9

16. O'Connor ML, McFadden SH. Development and psychometric validation of the dementia attitudes scale. Int J Alzheimers Dis. 2010;2010:454218.

17. Surr CA, Smith SJ, Crossland J, Robins J. Impact of a personcentred dementia care training programme on hospital staff attitudes, role efficacy and perceptions of caring for people with dementia: A repeated measures study. Int J Nurs Stud. 2016;53:144-51. https://doi.org/10.1016/j.ijnurstu.2015.09.009 PMid:26421910

18. Scerri, A, Scerri, C. 2013. Nursing students' knowledge and attitudes towards dementia-A questionnaire survey. Nurse Education Today, 33, 962-8. https://doi.org/10.1016/j. nedt.2012.11.001

19. Evripidou M, Charalambous A, Middleton N, Papastavrou E. Nurses' knowledge and attitudes about dementia care: Systematic literature review. WILEY Perspect Psychiatr Care. 2019;55(1):48-60. https://doi.org/10.1111/ppc.12291 PMid:29766513

20. Singh I, Kaur M, Rozier L, Evans L, Edwards C. Evaluation of dementia education at the early stages of professional training: Impact on knowledge and attitudes. J Alzheimers Neurodegener Dis. 2017;3:012.

21. Blaser R, Berset J. Setting matters: Associations of nurses attitudes towards people with dementia. Nurs Open. 2019;6(1):155-61. https://doi.org/10.1002/nop2.198 PMid:30534405

22. Yong M, Yoo C, Yang Y. Comparison of knowledge of and attitudes toward dementia between health-related and non-health-related university students. J Pshy Ther Sci. 2015;27(12):3641-3. https://doi.org/10.1589/jpts.27.3641 PMid:26834322

23. Martin LS, Gillies L, Coker E, Gnc C, Pizzacalla A, Ec RN, et al. An education intervention to enhance staff selfefficacy to provide dementia care in an acute care hospital in Canada: A nonrandomized controlled study. Am J Alzheimers Dis Other Demen. 2016;31(8):664-77. https://doi. org/10.1177/1533317516668574 PMid:27659392

24. Australian Institute of Health and Welfare. Dementia Care in Hospitals: Costs and Strategies. Canberra: Australian Institute of Health and Welfare; 2013. p. 111

25. Elvish R, Burrow S, Cawley R, Harney K, Graham P, Pilling M, et al. Getting to know me: The development and evaluation of a training programme for enhancing skills in the care of 
people with dementia in general hospital settings. Aging Ment Heal. 2014;18(4):481-8. https://doi.org/10.1080/13607863.20 13.856860

PMid:24328360

26. Kuske B, Luck T, Hanns S, Matschinger H, Angermeyer MC,
Behrens $\mathrm{J}$, et al. Training in dementia care: A cluster-randomized controlled trial of a training program for nursing home staff in Germany. Int Psychoger. 2009;21(2):295-308. https://doi. org/10.1017/s1041610208008387

PMid:19193252 